\title{
Trapping of Alpha Particles and Radon using Epoxy/Poly Vinyl Acetate Blend Foam
}

\author{
M.M El-Toony*1 and H.A.S.Aly ${ }^{2}$ \\ ${ }^{1}$ National Center for Radiation Research and Technology, Atomic Energy Authority, Egypt, 3Ahmad El-Zomr street, P.O.Box 29, Nasr City, Cairo \\ ${ }^{2}$ Physics Department, Faculty of Girls, Ain Shams Univ Heliopolis, Cairo
}

\begin{abstract}
Intelligent foam has been achieved by blending epoxy and poly vinyl acetate (PVA) with different ratios, foaming with nitrogen gas was further performed. It was found 25 Kilo gray irradiation electron beam obtained from accelerator was enough for compatibility and modified mechanical behavior. Water uptake to $50 \%$ was maintained over night and release was completed after 6 days at $20^{\circ} \mathrm{C}$. Thermal behavior testing revealed heat resistance up to $200^{\circ} \mathrm{C}$. Structure characterization was determined by FTIR spectroscopy while mechanical investigation was applied using hardness tester. The Foam blend was used to trap alpha particles emitted by ${ }^{239} \mathrm{Pu}$ and ${ }^{241} \mathrm{Am}$. Alpha counts were continuously recorded while water uptake was carried out until count cut off. Medium decontamination from radon was tracked via water uptaken foam using $773 \mathrm{ppm}{ }^{226} \mathrm{Ra}$ source until count cut. Durability of foam was measured by ten times repeatable water uptakes alpha particles and radon cut off showed no significant difference. Radon associated lead and bismuth were determined in the foam using SSNTD CR39 and a streamer detector and assured by using EDX which proved sorption of radon by specified foam.
\end{abstract}

Keywords: Polymer; PVA; Epoxy; Foam; Irradiation; Electron beam; Alpha particles; Radon; Trapping

\section{Introduction}

The exhalation and release of radon gas into the environment are the products of the radioactive decay chain of primordial uranium or thorium, specifically the isotope ${ }^{238} \mathrm{U},{ }^{235} \mathrm{U}$ and ${ }^{232} \mathrm{Th}$. The radon isotopes formed from these decay chains are ${ }^{222} \mathrm{Rn}$ ('radon'), ${ }^{219} \mathrm{Rn}$ ('actinon') and ${ }^{220} \mathrm{Rn}$ ('thoron'), while those of the radium isotopes are ${ }^{226} \mathrm{Ra}$, ${ }^{223} \mathrm{Ra}$ and ${ }^{224} \mathrm{Ra}$, respectively, in these chains [1]. Radon is a chemically inert noble gas with a half-life of about 3.8 days, while its decay products or progeny of various isotopes of bismuth (Bi), polonium (Po) and lead $\mathrm{Pb}$ generally forms solids at normal environmental conditions [2]. The half-lives of radon progeny vary from microseconds to minutes to years. The heavy-metal daughter-products are highly toxic and are readily adsorbed onto atmospheric particles, posing a significant health hazard, and inhalation of ${ }^{222} \mathrm{Rn}$, and its $\alpha$-emitting progeny ${ }^{218} \mathrm{Po}$ and ${ }^{214} \mathrm{Po}$, is believed [3] to provide the majority of the radiation dose received by the respiratory system. Despite the fact that high doses of ionizing radiation are detrimental, substantial data from experimental organisms ranging from protozoa to humans show that biological functions are stimulated by low dose of radiation [4,5]. "“Radiation hormesis" is the name given to the putative stimulatory effects of low level ionizing radiation $[4,6]$. In humans, radioactivity damages the sensitive inner lining of the lung, increasing the risk of lung-cancer. This is due to the trapping of radon and its decay products in the lungs. The association between enhanced levels of environmental radon and lungs increases the risk of lung-cancer [7-9]. Hence radon is recognised as a multiplicative factor in the incidence of lungcancer among smokers. It is estimated that the annual mortality from exposure to radon in buildings represents $9 \%$ of all deaths from lungcancer, and 2\% of all cancer deaths in Europe [8]. Since the total annual mortality from this type of cancer in the UK is between 30,000 and 35,000 [10], it is suggested that between 1800 and 2100 deaths annually are caused by exposure to radon and its progeny. Radon may be one of the oldest natural remedies of mankind dating back into ancient cultures and prehistoric times long before radon and radiation were known. Unlike many paramedical "treatments" including homeopathy or acupuncture, the beneficial effects of radon balneology appear now to be well established with several randomized double-blind studies which cannot simply be explained by psychosomatic or placebo effects. Responding to the threat to health raised by the presence of radon in domestic properties, the former U.K. National Radiological Protection Board (NRPB), established an action level of $200 \mathrm{~Bq} \mathrm{~m}^{-3}$ for domestic properties and designated a number of radon Affected Areas, geographical entities where more than $1 \%$ of the housing stock is predicted to have radon concentrations in excess of the Action Level [11]. Where elevated levels of domestic radon are discovered, householders are strongly encouraged to take steps to remediate this situation. In existing U.K. homes, the methods generally adopted to reduce indoor radon levels rely on two key processes, dilution and/or pressure change, achieved principally by the installation of a pressuremodifying sump, often in conjunction with an extraction fan [12]. The preferred approach for new-built houses is by installation of a radonproof membrane across the entire footprint of the house, with cavity trays protecting the walls. In higher-risk areas, this is supplemented with natural under-floor ventilation, in the case of suspended flooring, or by construction of a passive sump below the level of the groundfloor, in the case of ground-bearing concrete flooring. In either case, if the completed house is found to have an elevated radon level, these measures can be reinforced with a mechanical fan fitted to the sump to provide active sub-slab depressurization [13]. This work aims to study the decontamination of houses and difficult aeriated situations due to dangerous problematic radon and alpha particles. Prepare a foam blend

*Corresponding author: M.M El-Toony, National Center for Radiation Research and Technology, Atomic Energy Authority, Egypt, 3 Ahmad El-Zomr street, P.O.Box 29, Nasr City, Cairo, 11370 Tel: 20101318501; Fax: +20222944803; E-mail: Toonyoptrade@yahoo.com

Received November 03, 2011; Accepted January 11, 2012; Published January 16,2012

Citation: El-Toony MM, Aly HAS (2012) Trapping of Alpha Particles and Radon using Epoxy/Poly vinyl Acetate Blend Foam. J Material Sci Eng 1:102. doi:10.4172/2169-0022.1000102

Copyright: (c) 2012 El-Toony MM, et al. This is an open-access article distributed under the terms of the Creative Commons Attribution License, which permits unrestricted use, distribution, and reproduction in any medium, provided the original author and source are credited. 
of epoxy with polyvinyl acetate that can be used in decontamination from dangerous radon and alpha particles. The prepared foam was proved to possess hydrophilic and sufficient mechanical and thermal properties advantageous for its application. FTIR investigation proved compatibilization of the blend. Application of the synthesized blend foam for absorbing alpha particles and radon was successfully performed.

\section{Experimental Approach}

\section{Materials}

Blends were prepared using commercial grade phenyl epoxy and polyvinyl acetate. Nitrogen gas was used in foaming the blend supplied from Optco, Egypt. The PVA paste was solved into magnetically stirred distilled water for 3 hours at $80^{\circ} \mathrm{C}$ getting an emulsion with the concentration of $60 \%$.

\section{Method of preparation}

Epoxy/PVA was mixed to realize the optimum ratio which has good structure and best hydrophilic character. 20\%,30\%, 50\% and $70 \%$ by weigh of PVA were mixed with epoxy and a solidifying agent. The mixture was heated to reach the maximum compatibility then temperature was reduced to reach a very viscous state. Foaming of the blend was carried out for more than 5 hours till obtaining highly porous solid blend. Irradiation with different doses; 10, 25, 50, 75 and $100 \mathrm{KGy}$ by electron beam irradiation was applied to realize moderate porosity, best hydrophilicity and compatibility.

\section{Water uptake}

Water uptake/swelling behavior of resin was determined in water as a function of irradiation dose (KGy) and composition. Swollen polymers were wiped off with tissue paper to remove surface water then weighed immediately the percent swelling/ percent water uptake was calculated as:

$$
\text { Water uptake\% }=\frac{\text { weight of swollen blend resin-weight of dry blend resin }}{\text { weight of dry blend resin }} \times 100
$$

\section{Alpha measurements using streamer detector} $\mathrm{mm}^{2}$.

The effective area of detector is limited by the anode area; $120 \times 64$

Alpha particles from ${ }^{239} \mathrm{Pu}$ and ${ }^{241} \mathrm{Am}$ source were passed from a rectangular slit of $5 \mathrm{~mm}$ in depth and $20 \mathrm{x} 4 \mathrm{~mm}^{2}$ cross section area and $25 \mathrm{~mm}$. Normal air was used as the energy absorber to control the final alpha energies incident on the detector.

\section{CR-39 detectors}

The CR-39 detector was irradiated with alpha particles of $4 \mathrm{MeV}$ under normal incidence through a collimator. Two alpha sources were employed a planar ${ }^{241} \mathrm{Am}$ source main alpha energy of $5.49 \mathrm{MeV}$ and ${ }^{239} \mathrm{Pu}$ main alpha energy of $5.1 \mathrm{MeV}$. After irradiation, the detectors were etched in $6.25 \mathrm{~N}$ aqueous solution of $\mathrm{NaOH}$ maintained at $70^{\circ} \mathrm{C}$ in a water bath for 6 hours. The detectors were then taken out from the etchant, rinsed with distilled water and dried in air. The etched tracks were observed using an optical microscope fitted with an objective lens of 100 times magnification. At this magnification one counting field covers an area of 0.70 images on a monitor, after the polymeric material is presented to face the alpha $\mathrm{mm} 2$. The microscope image was viewed with a high-quality digital camera (TV camera), which is connected to a PC- to displays particles.

The radon detector chamber: The detector consists of cylindrical cups (air tide chamber) one as radon gas room with $6 \mathrm{~cm}$ height and 9.5 $\mathrm{cm}$ diameter. Created radon of ${ }^{226} \mathrm{Ra}, 733 \mathrm{ppm}$ activity, was allowed to pass through an open window to the other cup of chamber of $9.5 \mathrm{~cm}$ in radius and $16 \mathrm{~cm}$ in height, to find the detector CR39. This cup is sealed with silicon. The CR-39 on the top of the detector chamber is fixed to reduce any error that might be caused by any movement.

Tracks of radon alpha-particle produced in CR-39 detector: The measurements were carried out by repeated insertion the water uptaking foam between $\mathrm{T}_{1}$ and $\mathrm{T}_{2}$. The etched track recorded on CR39 unexposed detector represents background. To assure the trapping of radon by the foam 10 different fields were scanned at same conditions.

\section{EDX instrument}

Oxford-tests attached to Scan Electron Microscope (SEM), Joel5400, Japan.

Calibration data: Gain factor: 49.996, Live time: 80 Seconds.

Sample data: Total spectrum count: 875722 , Live time: 70 Seconds.

-System resolution: $173 \mathrm{eV}$.

-Accelerating voltage: $20.00 \mathrm{KV}$.

\section{Scientific equipments}

Hardness tester: Manual analogue instrument with pin produced by Baxio, UK.

FTIR characterization: The functional groups of the prepared polymer resin were studied using Mattson 1000, Pye-Unicam, England.

Thermalgravimetric analysis: Shimadzu TGA -50, Japan was used to characterize the polymer foam thermally.

\section{Results and Discussion}

\section{Scientific approach}

Depending on the fact that; lung's tissue is very sensitive and reactive for radon gas and/ or alpha particles. The authors design a polymer foam which somewhat resembles the lungs tissues. The foam's bottom was relatively hard in texture while it tended to decrease their hardness till it reached to soft at the top surface. Larger holes and bigger vaccuents at the top surface were observed while it decreased regularly till it reached to the least size at the bottom. Top surface is somewhat mucoid to facilitate each of alpha particles and radon gases to be cohered. Ageing test was investigated by exposing the polymer matrix to cosmic rays out door for two years. Ageing resulted in partially disappearance of holes and appearance of small cracks of the polymer matrix after one years while it enlarged by time until two years passage as it seen in figure 1 (A,B,C,D). Direct exposure to radon gas for 30 days conducted reduction of its weight and dimensions to about $10-15 \%$. These results may put a valuable spot of light on the treatment of the lung's cancer.

\section{FTIR characterization}

Evidence of blending and network formation was provided by the characterization of porous foam syntheses. Spectrum broad peak at $3400 \mathrm{~cm}^{-1}$ proved presence of carboxylic group of the acetate showing maximum intensity which assured finally blending of PVA with Epoxy. Three successive bands at 670,1300 and $1650 \mathrm{~cm}^{-1}$ reveals the presence of epoxy was obviously appeared. At $2200 \mathrm{~cm}^{-1}$ an obvious beak has been shown which is due to double bond between two carbon atoms 

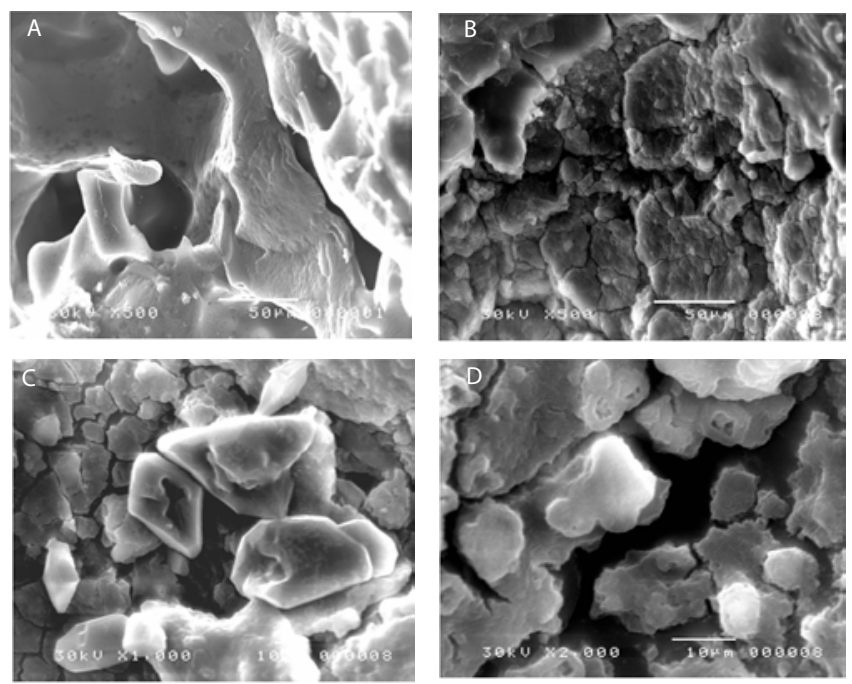

Figure 1: Effect of cosmic ray for different time on blend foam (PVA /Epoxy). (A) Top surface of fresh blend foam (PVA /Epoxy), (B) Ageing of the blend foam (PVA /Epoxy) matrix for 1 year exposing to cosmic ray, (C) Ageing of blend foam (PVA /Epoxy) matrix for 1.5 years exposing to cosmic ray years (D) Ageing of blend foam (PVA /Epoxy) matrix for 2 years exposing to cosmic ray.

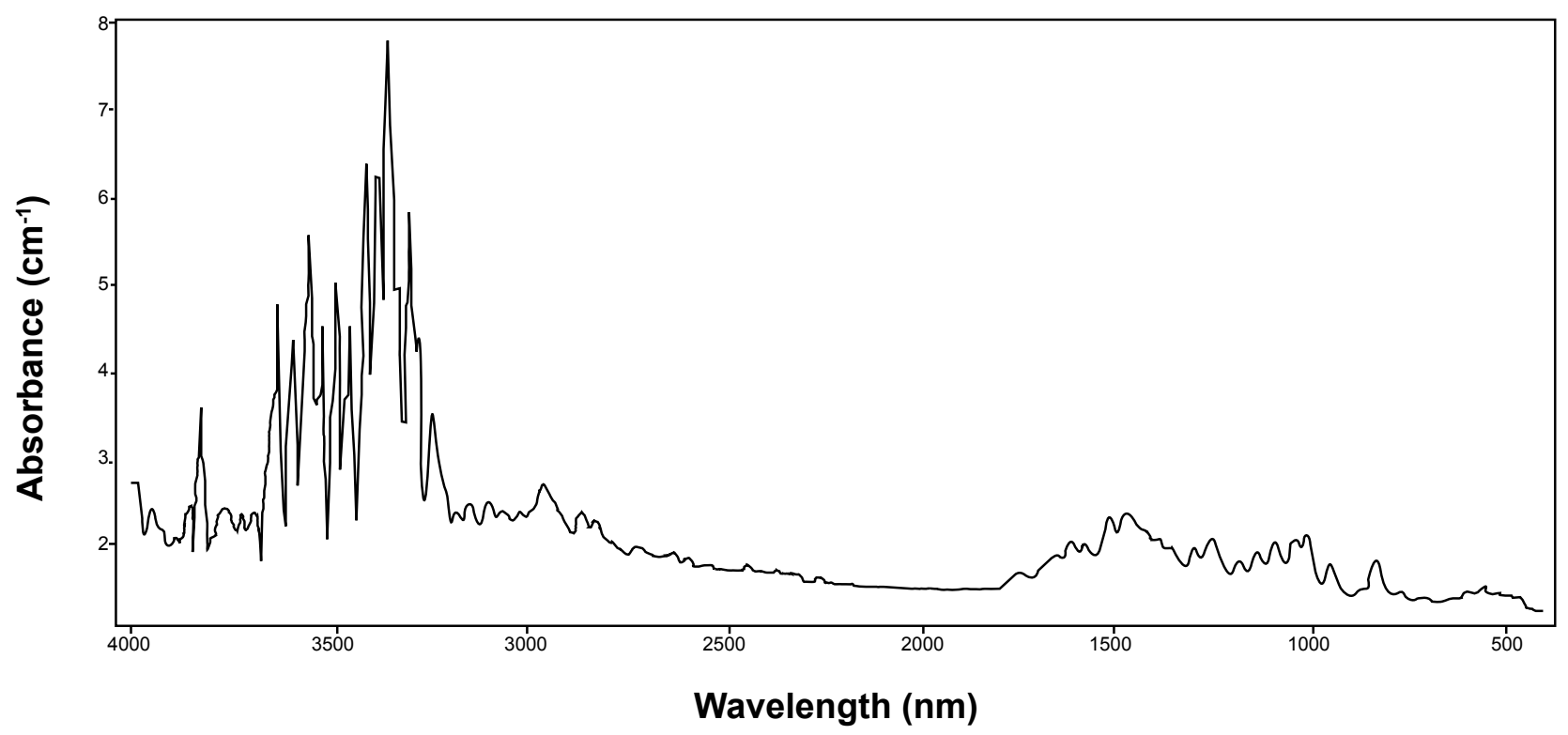

Figure 2: FTIR chart of Polyvinyl Acetate-Epoxy blend foam.

which as a result of vinyl group presence. These results proved that complete compatiblization of the polymer used within the blend and no reaction have been occurred between the polymers used except for finally mixing (Figure 2).

\section{TGA characterization}

The determination of this loss in weight is the principle of different variant of thermogravimetric analysis (TGA). The temperature at which the loss in weight occurs is considered to be the thermal resistance of polymer [14,15]. An improvement in thermal characteristics was detected as blending takes place. The blend showed high thermal resistance up to $200^{\circ} \mathrm{C}$ (the loss not exceed 7\%) this very small weight loss was due to blending of polyvinyl acetate to epoxy. Degradation of the blend in the range of temperature $200^{\circ} \mathrm{C}$ to $330^{\circ} \mathrm{C}$ was about $20 \%$. While the decay was reached to $35 \%$ from the starting weight due raise the temperature from $330^{\circ} \mathrm{C}$ to $400^{\circ} \mathrm{C}$. Slowing down of blend degradation was seen in the third division of the thermogram upon raising temperature to $580^{\circ} \mathrm{C}$. No step peak was observed proving reasonable compatibility in the entire thermal course (Figure 3 ).

\section{Mechanical properties}

Foam hardness: Hardness of the dry foam showed maximum reading of 50 shore-D then decreased upon soaking in water till 18 shore-D for foam surface after 7 days' water soaking. While the hardness of the bottom have a higher value reached to 36 shore-D after 10 days' water soaking as it seen in (table 1). These results proved 


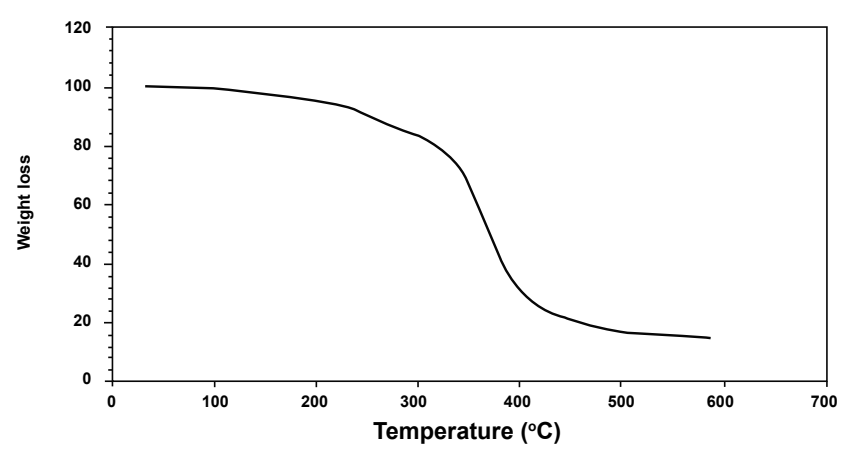

Figure 3: TGA graph of Polyvinyl acetate-Epoxy blend foam.

\begin{tabular}{|l|l|l|l|}
\hline No & $\begin{array}{l}\text { Time of water soaking } \\
\text { (day) }\end{array}$ & $\begin{array}{l}\text { Hardness of foam } \\
\text { surface (shore-D) }\end{array}$ & $\begin{array}{l}\text { Hardness of bottom } \\
\text { (shore-D) }\end{array}$ \\
\hline 1 & 0 & 58 & 65 \\
\hline 2 & 1 & 35 & 52 \\
\hline 3 & 2 & 30 & 47 \\
\hline 4 & 3 & 23 & 42 \\
\hline 5 & 5 & 20 & 39 \\
\hline 6 & 7 & 18 & 37 \\
\hline 7 & 10 & 18 & 36 \\
\hline
\end{tabular}

Table 1: Effect of water soaking of the blend foam (PVA/epoxy) on the hardness.

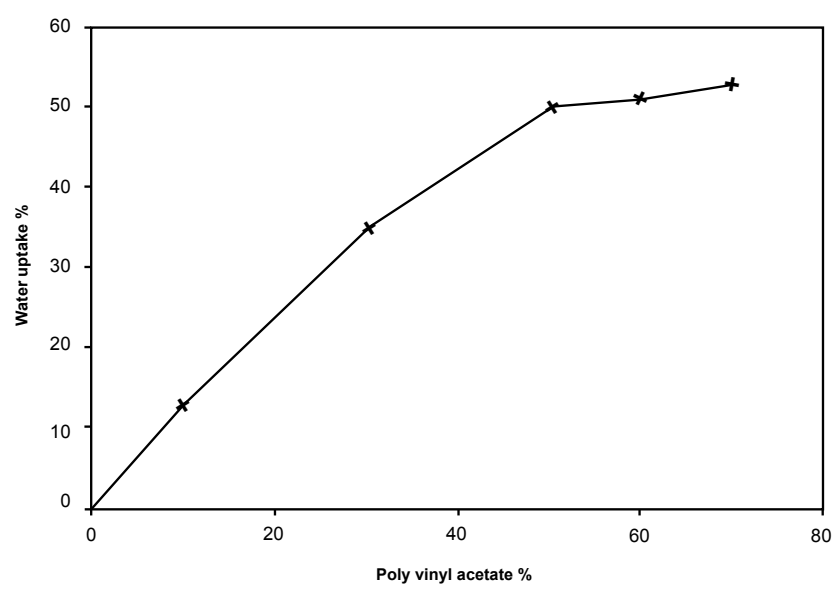

Figure 4: Effect of PVA\% of PVA / Epoxy blend foam on water uptake at $50 \%$ PVA, 25 KGy.

that; a firm structure is fixed and stable upon soaking for long time. Thus, the blend foam can be admitted durable for a wide range of tough applications including trapping of alpha particles and radon in different circumstances.

\section{Water uptake studies}

Water uptake of porous blend resin was studied as a function of composition, gamma irradiation dose. 50\% PVA composition of the blend showed maximum water uptake as shown in (Figure 4). Meanwhile $25 \mathrm{KGy}$ was the optimal dose for water uptake appeared obviously at (Figure 5). Foaming of blend remarkably improved water uptake. This may be accounted from increase in pore number, pore size and / or increase the dimensions of the foam formed leading to an increase in surface area allowable for capturing water molecules into net matrix of the resin.

Temperature is a very important factor influencing water uptake as raising up temperature may affect on active sites and mobility of water molecules leading to reduction the time needed for reaching maximum water uptake. (Figure6) shows that evenly composed blend irradiated with $25 \mathrm{KGy}$ demonstrated maximum uptake at $20^{\circ} \mathrm{C}$, meanwhile (Figure 7) exhibits the least soaking time 12 hours for achieving maximum water uptake.

\section{Trapping of alpha particles}

The energy of the alpha emitted is mildly dependent on the half-life for the emission process; with many orders of magnitude differences in half-life being associated with energy changes of less than $50 \%$. The energy of alpha particles emitted varies, with higher energy alpha particles being emitted from larger nuclei, but most alpha particles have energies of between 3 and $7 \mathrm{MeV}$, corresponding to extremely long to

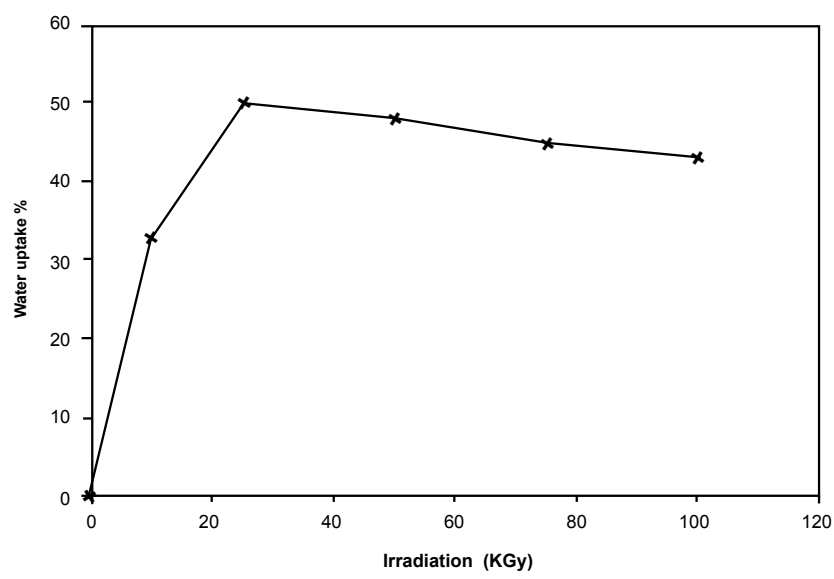

Figure 5: Effect of gamma irradiation dose of PVA / Epoxy blend foam on water uptake at $50 \%$ PVA, 25 KGy.

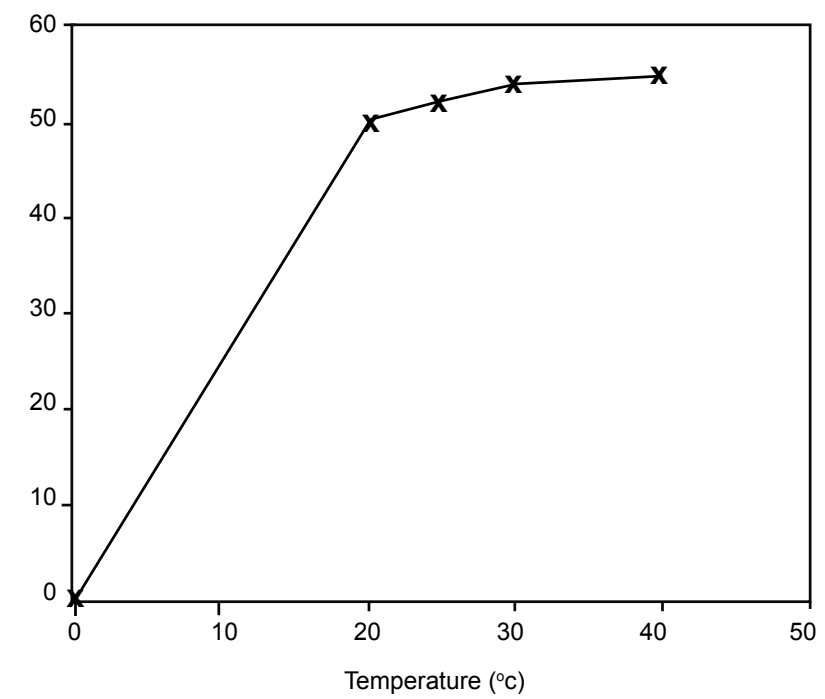

Figure 6: Effect of temperature $\left({ }^{\circ} \mathrm{C}\right)$ of PVA/ Epoxy blend foam on water uptake at $50 \%$ PVA, $25 \mathrm{KGy}$. 


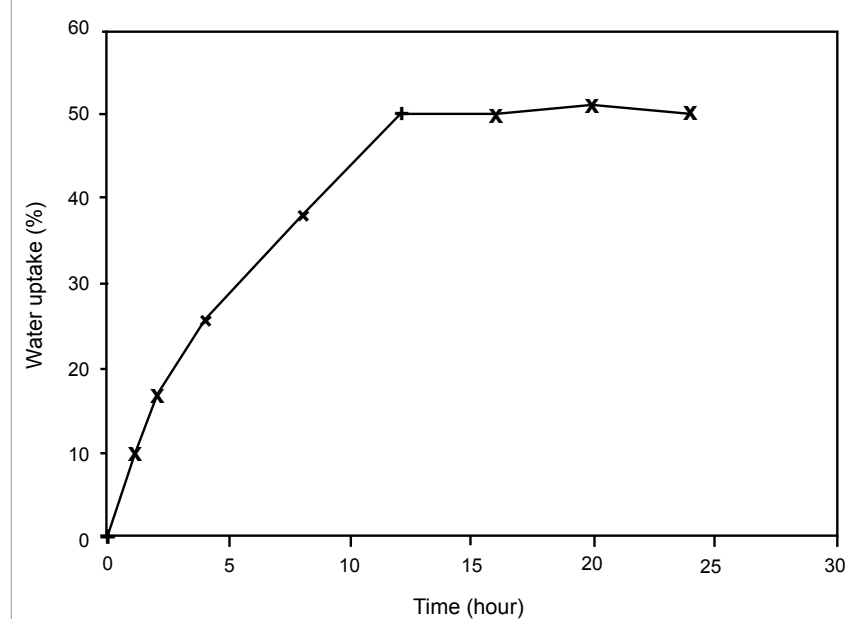

Figure 7: Effect of contact time (hour) of PVA/ Epoxy blend foam on water uptake at $50 \%$ PVA, $25 \mathrm{KGy}$.

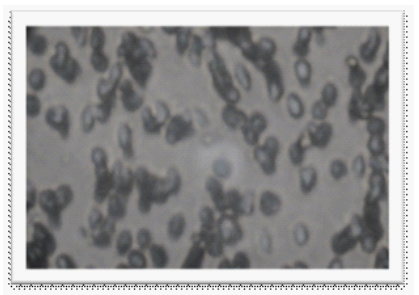

a) in the absence of the foam.

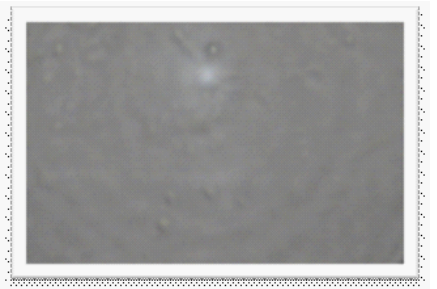

b) in the present of the foam.
Figure 8: Three-dimensional image (viewing directly from above) of replicas of tracks resulted from normally incident: ${ }^{241} \mathrm{Am} 5.49 \mathrm{MeV}$ alpha particles.

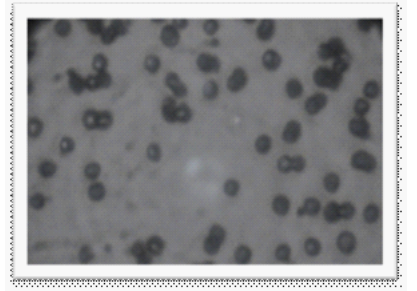

a) in the absence of the foam.

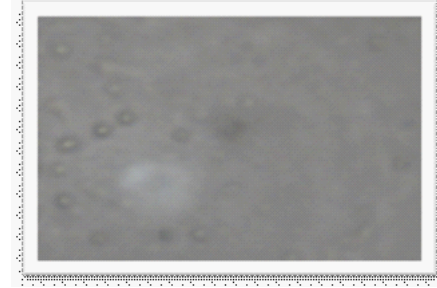

b) in the present of the foam
Figure 9: Three-dimensional image (viewing directly from above) of replicas of tracks resulted from normally incident: ${ }^{239} \mathrm{Pu} 5.1 \mathrm{MeV}$ alpha particles.

extremely short half-lives of alpha-emitting nuclides, respectively. This energy is a substantial amount of energy for a single particle, but their high mass means alpha particles have a lower speed (with a typical kinetic energy of $5 \mathrm{MeV}$, the speed is $15,000 \mathrm{~km} / \mathrm{s}$ which is $5 \%$ of the speed of light) than any other common type of radiation ( $\beta$ particles, $\gamma$ rays, neutrons, etc). Because of their charge and large mass, alpha particles are easily absorbed by materials, and they can travel only a few centimeters in air. They can be absorbed by tissue paper or the outer layers of human skin (about 40 micrometers, equivalent to a few cells deep). Because of the short range of absorption, alphas are not generally dangerous to life unless the source is ingested or inhaled, but then they become extremely dangerous. Because of this high mass and strong absorption, if alpha emitting radionuclides do enter the body (if the radioactive material has been inhaled or ingested), alpha radiation is the most destructive form of ionizing radiation. It is the most strongly ionizing, and with large enough doses can cause any or all of the symptoms of radiation poisoning. It is estimated that chromosome damage from alpha particles is about 100 times greater than that caused by an equivalent amount of other radiation. The alpha emitter polonium-210 is suspected of playing a role in lung cancer and bladder cancer related to tobacco smoking [16]. Not only do alphas themselves cause damage, but approximately equal ionization is caused by the recoiling nucleus after alpha emission, and this energy which may in turn be especially damaging to genetic material, since the positive cations of many soluble transuranic elements which emit alphas, are chemically attracted to the net negative charge of DNA, causing the recoiling atomic nucleus to be in close proximation to the DNA. The synthesized polymer foam was proved to be strongly efficient for decontaminating alpha particles from two sources as it illustrated in. $241^{\mathrm{Am}} 5.49 \mathrm{MeV}$ (Figure 8) and 239 $9^{\mathrm{Pu}} 5.1 \mathrm{MeV}$ (Figure 9) sources were used while the results using the foam showed completely getting rid of the alpha particles completely. Water swollen polymer play an important role in getting ride of alpha particles, at $30 \%$ by weight of water swell the foam is capable to completely trap alpha particles as it seen in (Figure 10).

\section{Trapping of radon gas}

The predecessors to radon in the chain are solids and will not migrate far from their place in the soil; radon is a gas and can migrate through a few feet of earth. Cohen [17] reported that on the average, about six atoms of radon emerge from every square inch of soil every second. Radon in outside air is diluted rapidly, but if it enters through a basement floor and is trapped in a tight house, it can reach high concentrations. From Lutgens [18] there is an estimate that the top 6 feet of soil from an average acre of land contains about $50 \mathrm{lbs}$ of uranium. This corresponds to about 2 to 3 parts per million. United States Environmental Protection Agency's (U.S. EPA) recommended "action level" of 4 picoCuries per liter of air (pCi/L) The U.S. EPA

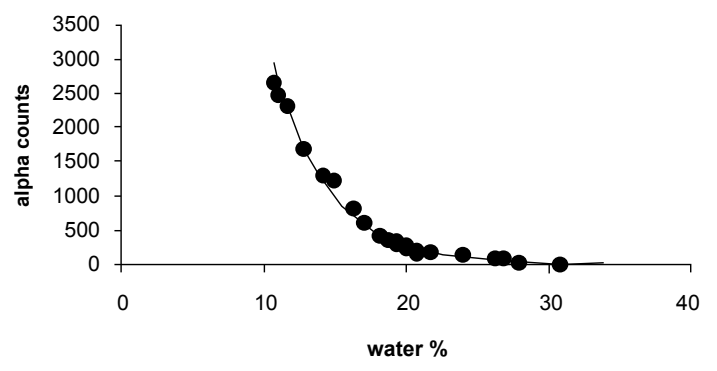

Figure 10: Effect of water content uptaken through foam matrix on alpha particles counting produced in streamer detector while using $5.1 \mathrm{MeV}$ alpha particles.
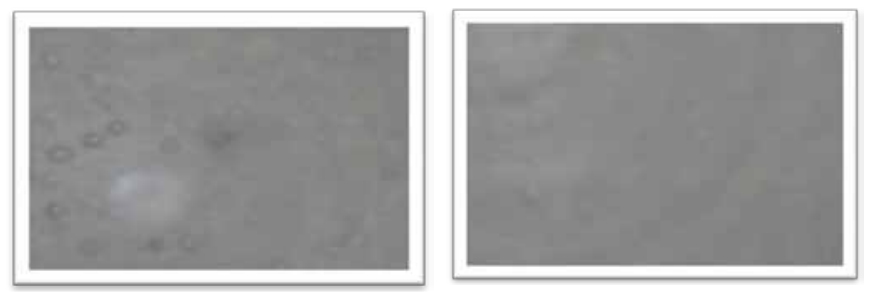

Figure 11: Tracks of Radon and Alpha -Particle Produced in CR-39 Detector, a)before insertion of epoxy/PVA foam. b)after insertion of epoxy/PVA foam. 


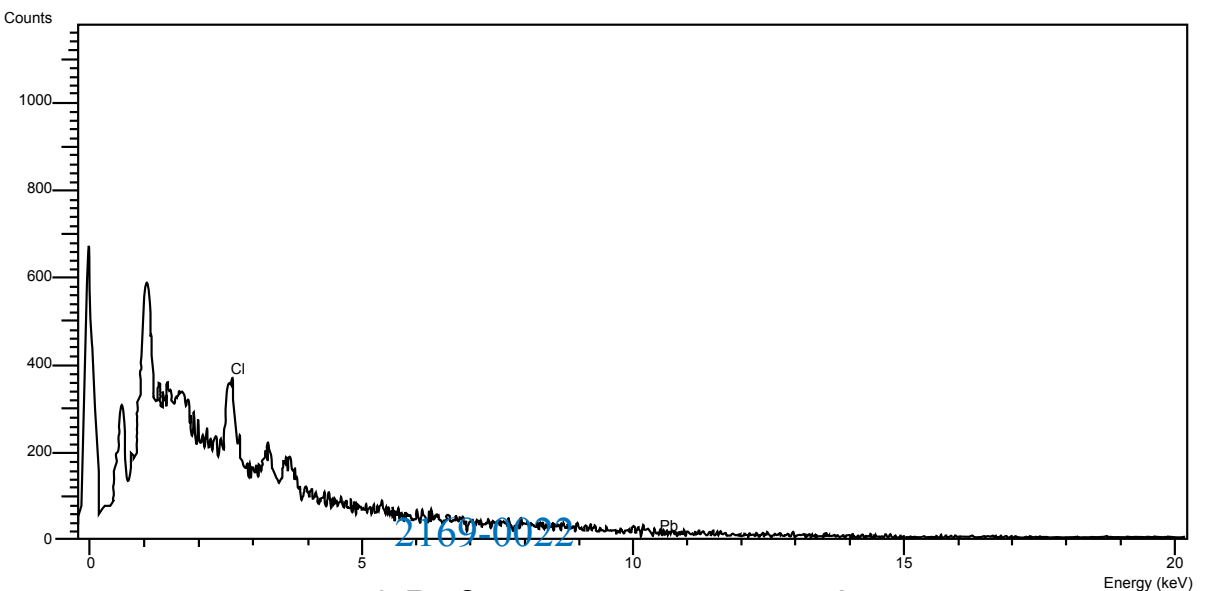

a) Before exposure to radon

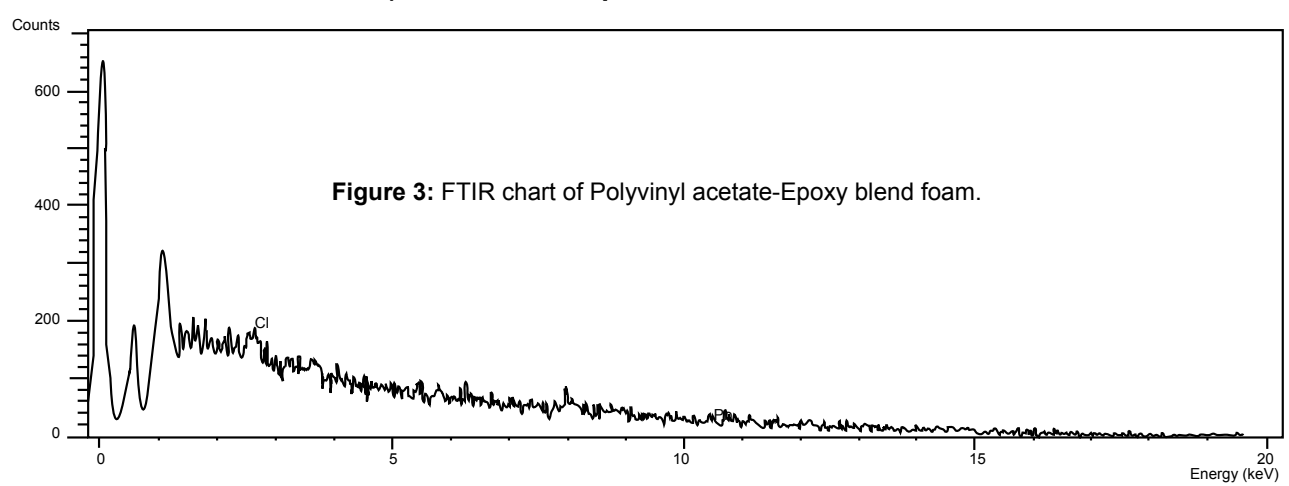

b) Radon exposure surface

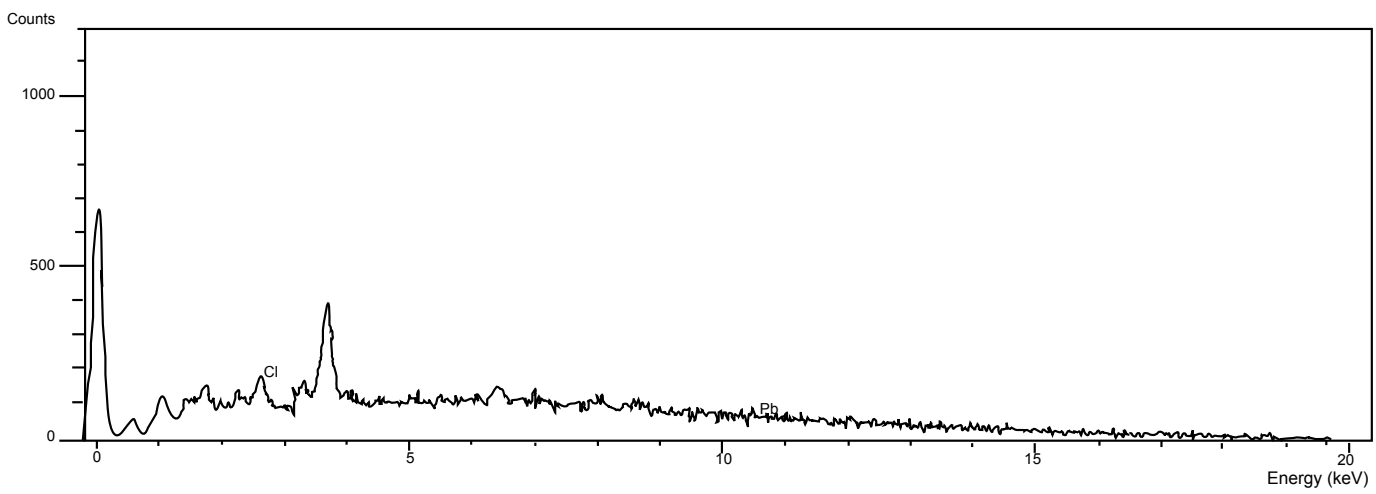

c) Radon exposure bottom

a) Before exposure to radon. b) Radon exposure surface. c) Radon exposure bottom.

Figure 12: TGA graph of Polyvinyl acetate-Epoxy blend foam.

and the U.S. Surgeon General recommend that people not be exposed to more than $4 \mathrm{pCi} / \mathrm{L}$ of radiation from radon on a long-term basis. The most effective and cost efficient method for radon reduction is "Active Soil Depressurization." This method collects radon from beneath building before it enters the structure, and vents the radon safely to the outside. The particular steps required to do this depend upon building's foundation. For homes built on crawl spaces, a high density polyethylene sheet is laid on the soil. The seams and edges are sealed, and a perforated pipe or drain mat is placed beneath the plastic. This pipe is connected to solid PVC piping and a fan, which creates a vacuum beneath the plastic. Radon is thus effectively collected and exhausted to a safe, outside location. Indoor radon concentrations reflect the balance between the rate of radon entry into a structure from all sources and the rate of radon loss by natural radioactive decay and by dilution by ventilating air. The rate of radon entry into a building is the sum of contributions from soil-gas (generally accepted, particularly for premises with high radon entry rates, as the principal source), from building materials [19-23] and less significantly in the UK, from well/ borehole water supplies [24] and the combustion of natural gas for cooking/heating [25]. Radon loss is dominated by ventilation rate, 
commonly expressed in units of air-change per hour and to a lesser extent, by natural radioactive decay (T1/2=3.6 days). While radon entry into a room from building materials is essentially diffusive, entry from the subsoil is pressure-driven, the necessary small depressurisation (a few Pascal) being readily generated by the effects of wind, indooroutdoor temperature differences, and the use of heating, ventilation and air-conditioning systems [26]. Gunby et al. [27] showed that the nature of the building materials used for both the walls and the floors in the rooms in which radon measurements were made were significant. Using brick walls as a basis for comparison, concrete walls increase the structural radon contribution by $20 \%$ and stone walls by $72 \%$; in contrast, wooden walls reduce the structural radon to $57 \%$ of the value associated with brick walls. Although this work acknowledged that building materials might be responsible for $20-50 \%$ of the radon in an average U.K. while radon entering the house by routes not influenced by sub slab depressurization, and radon emanating from the materials forming the structure of the house itself [20]. According to the efforts have been mentioned to reduce the radon concentrations in houses, building and others, new concept trials facing the radon risk, have performed. The Results shown in (Figure 11) confirm that the synthesized polymer foam is a promising material that can be used in getting ride off radon at a content of $30 \%$. This appearance may be due to solution of radon and alpha particles which facilitate sorption of radon's daughter to the foam active sites.

\section{Bismuth and lead decontamination}

The synthesized polymer foam suggests selective in removing lead and bismuth from water as shown in (Figure 12). Sorption of metals onto the foam active sites may be due to physical or chemical sorption. Solvation of metals produced by radon decay may ionize the metals, thus facilitate trapping by foam's active sites distributed all over the adsorbent. Affinity of the foam, contact time between metals and active sites, temperature of the reaction while physico-chemical characteristics of the foam are detrimental factors for getting ride off the harmful metals which severely polluted the environment. It also showed more than $140 \mathrm{ppm}$ of lead on the surface polymer while bottom abstracted about $25 \%$ of them which proved the reactivity of the polymer towards the radon daughter. Low percent $(25 \%)$ of radon can escape from the surface to be sorbed on the foam bottom while more is logically in-between. Bismuth and polonium have the same behavior towards the synthesized foam while their range is greatly less than lead. These results proved that; a composition of that hydrophilic foam physically and chemically is highly fitted to radon trapping purpose.

\section{Conclusion}

Radon and alpha particles are very dangerous sources of irradiation for human health and environment. Radon comprises about $54 \%$ of natural and synthetic irradiations. Specified polymer foam with compatible mechanical, hydrophilic and chemical behaviors strongly assist in reducing the negative impacts by completely cut off the beam. Thermal gravimetric analysis confirmed the usage of the blend for a wide range of temperature reached to $200^{\circ} \mathrm{C}$. Further endeavors must be done to improve practical preliminary prototypes before mass production application to be carried out.

\section{Acknowledgement}

The authors would like to express my deepest gratitude and thanks to Prof Dr. Hosnya Abou-Zaid the professor of nuclear physics, faculty of Girls, Ain Shams Univ. for helpful discussion and continuous interest.

The whole work and the experiment of detection of alpha particles and radon gas set up achieved in the nuclear research lab Physics Dept. Women College for Art, Science and Education, Ain Shams University. While all polymers synthesis and characterization was competed at NCRRT labs.

\section{References}

1. Mudd M.Gavin (2008) Journal of Environmental Radioactivity. J Environ Radioact 99: 288-315.

2. Cothern C.R, Smith J.E, (1987) (Eds.), Environmental Radon. Plenum Press, New York, USA, 376.

3. Darby S, Hill D, Doll R (2001) Radon a likely carcinogen at all exposures. Ann Oncol 12: 1341-1351.

4. Macklis RM, Beresford B (1991) Radiation hormesis. J Nucl Med 32: 350-359.

5. Calabrese EJ, Baldwin LA (2002) Comments on the article 'De>ning hormesis'. Hum Exp Toxicol 21: 111-114.

6. Luckey TD (1982) Physiological benefits from low level of ionizing radiation Health Phys 43: 771-789.

7. BEIR VI (1999) (Committee on Health Risks of Exposure to Radon), BEIR V (Committee on Health Risks of Exposure to (Radon), Health risks of exposure to radon, National Academy Press, Washington DC, USA ISBN, 05645-4 0-309.

8. Darby S, Hill DC, Auvinen A, Barross-Dios JM, Baysson H, et al. Radon in homes and risk of lung cancer: collaborative analysis of individual data from 13 European case-control studies. Brit Med J 330: 223-238.

9. Krewski D, Lubin JH, Zielinski JM, Alanja M, Catalan VS, et al. (2005) Residential radon and risk of lung cancer: a combined analysis of 7 North American case-control studies. Epidemiol 16: 137-145.

10. Department of Health (2001) Dataset HSQ14DT2: Deaths, Registrations: deaths by age, sex and underlying cause.

11. O'Riordan MC (1990) Human exposure to radon in homes: recommendations for the practical application of the Board's statement Docs NRPB 1: 17-32.

12. Scivyer CR (1993) Surveying dwellings with high indoor radon levels: a BRE guide to radon remedial measures in existing dwellings. London: Construction Research Publications.

13. Scivyer CR (2001) Radon protection for new buildings: a practical solution from the UK. Sci Total Environ 272: 91-96.

14. Korshaki VV (1997) The chemical structure and thermal character of polymer Keter press, 24.

15. EL-Toony] MM (2007) PH.D Thesis ,The Use of Ionization Radiation for the Modification of Some Polymeric Materials for Use in Practical Applications, Faculty of Science, El-Menofia University.

16. Radford, Edward P (1964) Polonium-210: A Volatile Radioelement in Cigarettes. Science 143: 247-249.

17. Cohen LB (1983) Before It's Too Late, Plenum Press.

18. Lutgens, Frederick K, Tarbuck, Edward J (2000) Essentials of Geology, 7th Ed, Prentice Hall.

19. Åkerblom GP, Andersson P, Clavensjo B (1984) Soil gas radon-a source for indoor radon daughters. Radiat Prot Dosimetry 7: 49-54.

20. European Commission (1999) Radiological protection principles concerning the natural radioactivity of building materials. Brussels: Directorate-General, Environment, Nuclear Safety and Civil Protection.

21. Bossew $P$ (2003) The radon emanation power of building materials, soils and rocks. Appl Radiat Isot 59: 389-392.

22. Denman AR, Groves-Kirkby CJ, Groves-Kirkby NP, Crockett NP, Phillips PS et al. (2006) Factors influencing bedroom and living-room radon levels in two storey dwellings. Proc $2^{\text {nd }}$ IRPA European Congress, Paris.

23. Denman AR, Groves-Kirkby NP, Groves-Kirkby CJ, Crockett RG, Phillips PS, et al. (2007) Health implications of radon distribution in living rooms and bedrooms in U.K. dewellings- a case study in North amptonshire Enternet 33: 999-1011.

24. Kendall GM (2004) Controls on radioactivity in water supplies in England and Wales, especial reference to radon J Radiol Prot 24: 409-412.

25. Dixon D (2001) Radon exposures from the use of natural gas in buildings Radiat Prot Dosimetry 97: 259-264.

26. Nazaroff WW, Nero AV (1988) Radon and its decay products in indoor air. New York: Wiley Inter science.

27. Gunby JA, Darby SC, Miles JC, Green BM, Cox DR (1993) Factors affecting indoor radon concentrations in the United Kingdom. Health Phys 64: 2-12. 